\title{
"Beta" with "Size Premium" an Augmented Approach in the Frontier Equity Market: Evidence from Dhaka Stock Exchange
}

\author{
Mahfuza Khatun ${ }^{1}$ and K. M. Zahidul Islam ${ }^{2}$
}

\begin{abstract}
Traditionally, firm size has adopted in numerous heuristic asset pricing models as a determining factor of expected stock returns. So far as like systematic risk "beta", there is diminutive consensus over the magnitude and firmness of the "size" premium. Converging on the controversy this article attempts to examine the traditional Capital Asset Pricing Model (CAPM) and "size" augmented CAPM in the Dhaka Stock Exchange (DSE). The goal of this article is to examine the impact of an overall market factor and factor related to the firm size risk on expected stock returns at the portfolio level. Our sample encompasses non-financial stocks listed in DSE, with daily observations starting from January 2014 to December 2018. Depending on Market Capitalization and Book-to-Market Ratios we construct nine different portfolios, Ordinary Least Square (OLS) regression methodology is used to examine the models. Unlike common reckoning, we observe the strong existence of the "size" effect in frontier equity market DSE and has a tangible impact on explaining expected stock returns at the portfolio level. Additionally, the "size" augmented Capital Asset Pricing Model explains DSE better than the standard CAPM, may indeed be a good tool for a realistic assessment of the expected asset returns, and can improve the description of equilibrium in the Frontier equity market DSE.
\end{abstract}

JEL classification numbers: E44, G11, G12.

Keywords: Capital Asset Pricing Model (CAPM), Size Premium, Frontier Equity Market.

\footnotetext{
1 Associate Professor, Department of Finance \& Banking, Jahangirnagar University.

2 Professor, Institute of Business Administration, Jahangirnagar University.
} 


\section{Introduction}

No financial theory is a perfect representation of reality. A rudimentary question in finance that has not yet been fully answered is how the expected return relates to the risk associated with an investment. Around the 1930s, the thought of portfolio formation was well established within the minds of knowledgeable investors. In 1938, John Burr William's captured the thinking of the portfolio formulation by framing the "dividend discount model" (William, 1938). Meaningful theories of investor's risk preferences and decision-making under uncertainty came into light between the 1940s and 1950s, especially through the work of Neumann and Morgenstern (1944). In such a scenario, the Capital Asset Pricing Model (CAPM) evolved and considered the first comprehensible mathematical framework for exploring the risk-return relationship of an investment. The model was developed in the early 1960s by William Sharpe (1964) and Linter (1965). Eugene F. Fama once a great advocate of CAPM, later in 1992 questioned the validity of CAPM examining the US market. They did not find anything substantial between average return and beta, however, in the same study, they observe two significant risk factors namely "size" and book-to-market equity in explaining the variation in average returns. Fama and French (1993) proposed a multifactor asset pricing model that coincides with market risk, "size" and "book to market" equity are two additional risk factors needed to explain the variation in average returns.

Around the early eighty's, the very beginning of the earliest days of empirical work in academic finance, the size effect was the first market anomaly to challenge the standard asset pricing model and prompt arguments about market efficiency. Numerous empirical studies show that companies of smaller size are associated with more risk and, therefore, they have a greater cost of capital. In either way, the idea that smaller firms on average generate higher stock-market returns compares to their large competitors, even if after risk adjustment it was an unwavering fact of financial markets has been in trend for decades. Banz (1981) and Reinganum (1981) study outcome favor this trend to establish that small-caps outperformed on average the market index.

In this study, we followed Fama and French (1993) approach where the size effect is analyzed with reference to standard CAPM. Henceforth, the objective of this study is to examine the excess returns of the size sorted portfolios comparing with commonly used asset-pricing models and by what means the models capture the average returns of stock in DSE. Nevertheless, our research limitation is that we have not attempted to further clarify how precisely the market proxy used approximated the true market portfolio. The rest of this study is structured as follows. Section 2 reviews the literature relating to risk-return relationship and the size anomaly. Section 3 provides the dataset and methodology, Section 4 offers the result discussion and Section 5 concludes the study. 


\section{Literature Review}

This evidence Fama (1993) was key to the growth of small-cap mutual funds that capitalized on the size premium. In reality, the discovery of the size effect spurred a series of small-cap indices and active funds to a point in which the investment terrain has reshaped and is now classified into large and small stock universes. Despite its grand appearance by Banz (1981) as an asset pricing anomaly in financial literature, within a short period "size effect" has gone under debate. This debate started when Keim (1983) and few other scholars (See Brown et al.,1983; Schultz, 1983; Stoll and Whaley, 1983) noted that the "size effect" may have disappeared. Keim (1983) examine NYSE and AMEX common stocks month-bymonth and observed that the relation between abnormal returns and size is always negative. Prior research of Dimson and Marsh (1999), Horowitz et al. (1999) Hirshleifer (2001) Schwert (2003) Cochrane (2005) concluded similarly rather than a proposing different explanation for the disappearance of size effect only. However, in the last decade, "size effect" seems to reappear as an anomaly in asset pricing. Though in this decade findings of Brailsford et al. (2012), Dou et al. (2013), Cakici and Tan (2014), and Chiah et al. (2016) denies the significant existence of "size effect", in contrary C. Ang (2018), Atanasov and Nitschka (2017), Gaunt (2015) and De Moor and Sercu (2013) in their study reaffirms the size effect anomaly and most importantly the relationship between abnormal return and size anomaly is observed substantial.

Most of the previous studies regarding asset pricing anomalies heavily focused on developed markets including very few in the emerging markets. Since by virtue frontier markets are characterized as inefficient market, application of asset pricing models regarding those markets is observed rarely. In this paper, we try to explore the systematic risk-return relationship at the portfolio level and additionally added between expected return and firm size for data from the Dhaka Stock Exchange (DSE), a frontier equity market during 2014 to 2018 . The essence of this study is to interpret whether an investor with a frontier market approach can take benefit of the reality of such an anomaly to generate statistically significant abnormal returns. Typically, international investor's portfolios have a habit of being prejudiced in the direction of the largest and most liquid listed companies. Hence, these aftermaths are mostly useful to those international investors as well as for local investors of frontier equity market DSE.

\section{Data and Methodology}

\subsection{Data Source}

Daily data of listed stocks on the DSE is used in this study. The sampling period for this paper extends from January 1, 2014, to December 31, 2018, within five years, since beta calculated over a longer period may lead to biased results as the beta may change over the period (Bartholdy and Peare, 2005). Daily returns are calculated as differences in price at closing. Data used include net asset value (NAV), market capitalization (MC), the number of shares, and the year-end closing 
price of the studied companies. The number of stocks outstanding and the year-end closing price is used to calculate MC. NAV and the year-end closing price are the inputs used to calculate Book-to-Market (BMR) Ratio. The yield on the 91 days Treasury bill (TB) taken from the Bangladesh Bank Quarterly report, and used as an approximation of the risk-free rate. The present study considered DSE 30 Index (DS 30) is developed by leading index providers S\&P Dow Jones as a proxy from which the overall market returns are calculated. The excess return of the market is the return of the market over the risk-free return.

\subsection{Sample}

In this study, non-financial companies are considered following the criteria set by Fama and French $(1992,1993)$ and recently followed by Pena et al. (2010), Hasan et al. (2011), Gabriel (2014), Acheampong and Swanzy (2016), Ajlouni and Khasawneh (2017). Financial companies do not indicate the same meaning as nonfinancial firms. Hence, the study sample comprises all companies in DSE in all cases, excluding banks, insurance, finance company, and mutual funds. In addition, stocks having negative NAV and whose return data are not available for the full year, reasonably excluded from the sample. Partitioning companies into market equity sizes perform by following Basiewicz and Auret (2010) application. Based on the above criteria, the present study covers 138 companies in 2014; 163 companies in 2015; 174 companies in 2016; 177 companies in 2017, and 186 companies in 2018 and considered as a sample.

\subsection{Portfolio Construction}

Considering the "size" and number of eligible companies, we construct nine portfolios considering the Market Capitalization (MC) and Book-to-Market Ratios (BMR) of the companies. Here stocks are divided into three MC and three BMR set for the bottom 30\% (Low, 'L'), middle 40\% (Medium ' $M$ ',) and the Higher 30\% (High, 'H') by following Karp and Vuuren, (2017), Eraslan, (2013), Bhatnagar and Ramlogan, (2012), Djajadikerta and Nartea, (2005), and Connor and Sehgal, (2003). When divided MC into three parts, the first part named is MC1 (Low Market Capitalization), the second part is MC2 (Medium Market Capitalization), and the third part is MC3 (High Market Capitalization). In the same way, BMR is divided into three parts. The first part is named BMR1 (Low Book-to-Market Ratios), the second part as BMR2 (Medium Book-to-Market Ratios), and the third part as BMR3 (High Book-to-Market Ratios). According to these, nine portfolios are constructed by combining the three size portfolios and three Book-to-Market portfolios, thereafter it produces a $3 \times 3$ matrix of stock portfolios, which is visualized in Table 1 . 
Table 1: 3x3 Matrix of nine Portfolio formed on MC and BMR

\begin{tabular}{|c|c|c|c|c|}
\hline MC (Size) & Low & Medium & High & \\
\hline Small & S/L & S/M & S/H & \\
\hline Medium & M/L & M/M & M/H & \\
\hline Big & B/L & B/M & B/H & \\
\hline & & & & BMR \\
\hline
\end{tabular}

\subsection{Estimation methodology}

To estimate different factor models we used the Ordinary Least Squares (OLS) method in regression analysis. Time Series Regression (TSR) test for evaluating the performance of portfolio returns. This study follows the same Fama and French (1993) approach to measure the predictive capability of the stock risk-return relationship and whether there is the existence of a "size" effect at the portfolio level in DSE. There are several indicators to measure firm size, however, in this paper we consider the value of firm's stock capitalization (Fama and French, 2012) to measure as size factor and used. In order to estimate "size" augmented CAPM and standard CAPM, we used the OLS method in regression analysis. In regression analysis, we included Heteroskedasticity and Autocorrelation Consistent Covariance (HAC) method since it gives consistent estimates of standard errors (Minovic and Zivkovic, 2012). We used the $\mathrm{R}^{2}$ determination coefficient, F-test for regression significance, and t-test for parameters significance to check the adequacy of the model, we have chosen a model that best describes the equilibrium of the DSE.

\subsubsection{Independent Variable}

\subsubsection{Excess Return on the Market (RM-RF)}

It is the daily changes in DSE 30 Index (DS30) (proxy for Market Return) subtracted from the Risk Free Rate of Return $\left(R_{f}\right)$ (Converted 91 days T-bill into daily Risk Free Rate of Return).

\subsubsection{Small minus Big $(S M B)$}

Size Premium or Small minus Big (SMB) represents the premium required by investors as a reward for bearing the size risk, which is the difference between the daily return on a portfolio of small stocks and the portfolio of big stocks at time ${ }_{t}$ (Fama and French, 1993; Karp and Vuuren, 2017). SMB is measured as:

$$
S M B=\frac{1}{3}(\mathrm{~S} / \mathrm{L}+\mathrm{S} / \mathrm{M}+\mathrm{S} / \mathrm{H})-\frac{1}{3}(\mathrm{~B} / \mathrm{L}+\mathrm{B} / \mathrm{M}+\mathrm{B} / \mathrm{H})
$$




\subsubsection{Dependent Variables}

\subsubsection{Expected Excess Return of a Portfolio (RP. $R F)$}

It is the daily excess rate of return for the portfolios, which is measured as the rate

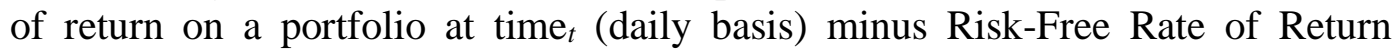
(Converted 91 days $t$-bill into daily Risk-Free Rate of Return). The excess returns on the nine portfolios are used as dependent variables in the case of the Time Series Regressions (TSR).

$R P_{t}-R F_{t}=a_{0}+\beta_{1}\left(R M_{t}-R F_{t}\right)+\varepsilon_{t}$

Where

$R P_{t}=$ Total Return of a Portfolio at time $e_{t}$

$R F_{t}=$ Risk Free Rate of Return at time $t_{t}$

$R M_{t}=$ Total Market Portfolio return at time ${ }_{t}$

$R P_{t}-R F_{t}=$ Expected Excess Return of a Portfolio

$R M_{t}-R F_{t}=$ Excess Return on the Market Portfolio

$\beta_{1}=$ Factor Coefficient

$\varepsilon_{t}=$ Error term

In line with the basic CAPM equation (equation 1) one additional factor, $S M B_{t}$, is added in the CAPM model to observe the size effect as well as its impact on the explanatory power of the model in DSE. The regression equation is specified as follows:

$R P_{t}-R F_{t}=a_{0}+\beta_{1}\left(R M_{t}-R F_{t}\right)+\beta_{2} S M B_{t}+\varepsilon_{t}$

Where

$R P_{t}=$ Total Return of a Portfolio at time $e_{t}$

$R F_{t}=$ Risk Free Rate of Return at time $t_{t}$

$R M_{t}=$ Total Market Portfolio return at time ${ }_{t}$

$R P_{t}-R F_{t}=$ Expected Excess Return of a Portfolio

$R M_{t}-R F_{t}=$ Excess Return on the Market Portfolio

$S M B_{t}=$ Size Premium (small minus big)

$\beta_{1,2}=$ Factor Coefficients

$\varepsilon_{t}=$ Error term 


\section{Main Results}

Table 2: Descriptive Statistics of the Independent Variables and nine Portfolios for the year 2014 to 2018.

\begin{tabular}{|l|c|c|c|c|}
\hline Portfolio & Mean & Std. Dev. & Minimum & Maximum \\
\hline $\mathrm{S} / \mathrm{L}$ & 0.0006 & 0.0096 & -0.0327 & 0.0973 \\
\hline $\mathrm{S} / \mathrm{M}$ & -0.0001 & 0.0096 & -0.0387 & 0.0479 \\
\hline $\mathrm{S} / \mathrm{H}$ & -0.0003 & 0.0107 & -0.054 & 0.0416 \\
\hline $\mathrm{M} / \mathrm{L}$ & 0.0003 & 0.0091 & -0.0283 & 0.1004 \\
\hline $\mathrm{M} / \mathrm{M}$ & -0.0004 & 0.0098 & -0.0412 & 0.0539 \\
\hline $\mathrm{M} / \mathrm{H}$ & -0.0006 & 0.0103 & -0.0735 & 0.0475 \\
\hline $\mathrm{B} / \mathrm{L}$ & 0.0006 & 0.0078 & -0.0333 & 0.0985 \\
\hline $\mathrm{B} / \mathrm{M}$ & -0.0002 & 0.0073 & -0.0287 & 0.0361 \\
\hline $\mathrm{B} / \mathrm{H}$ & -0.0004 & 0.0076 & -0.0465 & 0.0298 \\
\hline$R M_{t}-R F_{t}$ & -0.0001 & 0.0072 & -0.0284 & 0.0373 \\
\hline$S M B_{t}$ & 0.00007 & 0.0066 & -0.0249 & 0.0289 \\
\hline
\end{tabular}

Source: Authors own calculation

Table 2 shows mean, standard deviation, minimum and maximum of nine portfolios (S/L, S/M, S/H, M/L, M/M, M/H, B/L, B/M, and B/H) for the study period. Excess Return on the Market Portfolio $\left(R M_{t}-R F_{t}\right)$, have negative mean, however, for $S M B_{t}$ portfolio returns have positive mean. It confirms that the return of small firms is higher than those of large firm. 
Table 3: The Capital Asset Pricing Model (CAPM): Excess Return on the Market Portfolio $\left(R M_{t}-R F_{t}\right)$ is Independent Variables and the Excess Rates of Return of the nine Portfolios are Dependent Variables (Year: 2014 to 2018).

\begin{tabular}{|c|c|c|c|c|c|c|c|c|c|c|c|c|}
\hline \multicolumn{13}{|c|}{$R P_{t}-R F_{t}=a_{0}+\beta_{1}\left(R M_{t}-R F_{t}\right)+\varepsilon_{t}$} \\
\hline \multirow{3}{*}{ Portfolio } & \multicolumn{3}{|c|}{ Book-to-Market Ratio } & \multicolumn{3}{|c|}{ Book-to-Market Ratio } & \multicolumn{3}{|c|}{ Book-to-Market Ratio } & \multicolumn{3}{|c|}{ Book-to-Market Ratio } \\
\hline & LOW & MEDIUM & $\mathrm{HIGH}$ & LOW & MEDIUM & HIGH & LOW & MEDIUM & HIGH & LOW & MEDIUM & $\mathrm{HIGH}$ \\
\hline & \multicolumn{3}{|c|}{$a_{0}$} & \multicolumn{3}{|c|}{$\beta_{1}$} & \multicolumn{3}{|c|}{ t- statistic } & \multicolumn{3}{|c|}{ P Value } \\
\hline $\mathrm{MCl}$ & 0.0007 & -0.00005 & -0.000 & 0.2898 & 0.4816 & 0.4664 & 6.3457 & 8.4181 & 7.8694 & 0 & 0 & 0 \\
\hline $\mathrm{MC2}$ & 0.0004 & -0.0003 & -0.000 & 0.4072 & 0.5829 & 0.571 & 9.4933 & 9.3295 & 9.5902 & 0 & 0 & 0 \\
\hline $\mathrm{MC3}$ & 0.0006 & -0.0001 & -0.000 & 0.2939 & 0.4737 & 0.461 & 9.1964 & 10.8953 & 11.451 & 0 & 0 & 0 \\
\hline \multicolumn{2}{|c|}{ Determination } & \multicolumn{4}{|c|}{ Adjusted $\mathbf{R}^{2}$} & & & & & & & \\
\hline MC1 & & 0.046 & & 0.1306 & 0.0971 & & & & & & & \\
\hline MC2 & & 0.103 & & 0.1814 & 0.1589 & & & & & & & \\
\hline MC3 & & 0.073 & & 0.2165 & 0.1917 & & & & & & & \\
\hline
\end{tabular}

Source: Authors own calculation

The present study shows that the market factor beta features a significant positive relationship with stocks' excess returns altogether nine portfolios. The coefficients of the small firm portfolios are above the large firms' portfolios and therefore the difference between the average small firm portfolios slope and the average large firm portfolios slope is 0.003067 . This finding implies that when the size factor increases by one unit, the stock return for the small portfolios also increases by 0.003067, which is above the large portfolios on average. For medium-firm portfolios, the coefficients are higher also than the large firms' portfolios are. Consequently, the difference of slope value between the average medium-firm portfolios and the large firm portfolios is 0.110833 . In addition, the average slope value for the high BMR portfolios market factor is 0.169167 and this value is higher than those of low BMR portfolios market factor. It designates that when the BMR increases by one unit, the stock return for the high BMR portfolios also increases by 0.169167 and it is higher than the low BMR portfolios on average. The average slope for the medium BMR portfolios market factor is 0.182433 and this value is higher than the low BMR portfolios market factor. These findings reveal that the firm size exists on the DSE and these findings are consistent with the findings of previous studies (Fama and French, 1992; Fama and French, 1993; Drew et al., 2003). The values of adjusted $\mathrm{R}^{2}$ for nine portfolios are ranging from $4.61 \%$ to $21.65 \%$. This result indicates that the CAPM performs rather weakly in predicting the variation of the stock's return at the portfolio level in DSE. The earlier study of 
Ajlouni and Khasawneh (2017); Karp and Vuuren (2017); Hanif and Bhatti (2010); Bajpai and Sharma (2015); Ansari (2000) Gupta and Sehgal (1993) also demonstrated similar findings.

Table 4 shows the results of CAPM with the size premia $\left(S M B_{t}\right)$ on DSE. The purpose is to check whether the presence of the size effect is or not and additionally patterned the explanatory power of the size augmented CAPM in DSE. After adding explanatory variable size premia $\left(S M B_{t}\right)$, the average adjusted $\mathrm{R}^{2}$ of nine portfolios increased to $30.78 \%$ from $13.31 \%$, which confirms a round about $130 \%$ rise in the explanatory power of the model. For small firm portfolio, size premia spotted more dominant and therefore the average adjusted $\mathrm{R}^{2}$ value rises to $54.03 \%$ from $9.13 \%$.

Table 4: The CAPM with SMBt: Excess Return on the Market Portfolio (RMt-RFt) and the SMBt are Independent Variables and the Excess Rates of Return of the nine Portfolios are the Dependent Variables (Year: 2014 to 2018).

\begin{tabular}{|c|c|c|c|c|c|c|c|c|c|c|c|c|}
\hline \multicolumn{13}{|c|}{$R P_{t}-R F_{t}=a_{0}+\beta_{1}\left(R M_{t}-R F_{t}\right)+\beta_{2} S M B_{t}+\varepsilon_{t}$} \\
\hline \multirow{3}{*}{ Portfolio } & \multicolumn{3}{|c|}{ Book-to-Market Ratio } & \multicolumn{3}{|c|}{ Book-to-Market Ratio } & \multicolumn{3}{|c|}{ Book-to-Market Ratio } & \multicolumn{3}{|c|}{ Book-to-Market Ratio } \\
\hline & LOW & MEDIUM & HIGH & LOW & MEDIUM & HIGH & LOW & MEDIUM & HIGH & LOW & MEDIUM & $\mathrm{HIGH}$ \\
\hline & \multicolumn{3}{|c|}{$a_{0}$} & \multicolumn{3}{|c|}{$\beta_{1}$} & \multicolumn{3}{|c|}{ t- statistic } & \multicolumn{3}{|c|}{ P Value } \\
\hline MC1 & 0.0006 & -0.0001 & -0.0003 & 0.2869 & 0.4787 & 0.4628 & 9.133 & 11.037 & 11.803 & 0 & 0 & 0 \\
\hline MC2 & 0.0003 & -0.0003 & -0.0006 & 0.4063 & 0.5821 & 0.5694 & 10.287 & 9.768 & 10.818 & 0 & 0 & 0 \\
\hline \multirow[t]{2}{*}{ MC3 } & 0.0006 & -0.0001 & -0.0004 & 0.294 & 0.4739 & 0.4605 & 9.202 & 10.846 & 11.783 & 0 & 0 & 0 \\
\hline & \multicolumn{3}{|c|}{$a_{0}$} & \multicolumn{3}{|c|}{$\beta_{2}$} & \multicolumn{3}{|c|}{ t- statistic } & \multicolumn{3}{|c|}{ P Value } \\
\hline MC1 & 0.0006 & -0.0001 & -0.0003 & 0.9299 & 0.9467 & 1.168 & 9.133 & 24.455 & 26.989 & 0 & 0 & 0 \\
\hline MC2 & 0.0003 & -0.0003 & -0.0006 & 0.2953 & 0.2899 & 0.5251 & 6.965 & 5.307 & 9.665 & 0 & 0 & 0 \\
\hline MC3 & 0.0006 & -0.0001 & -0.0004 & -0.053 & -0.0746 & 0.1722 & -1.382 & 10.846 & 3.92 & 0.167 & 0.06 & 0 \\
\hline Determination & \multicolumn{4}{|c|}{ Adjusted $\mathbf{R}^{2}$} & & & & & & & & \\
\hline MC1 & 0.4 & 52 & 0.556 & 0.613 & & & & & & & & \\
\hline MC2 & 0.1 & 49 & 0.219 & 0.272 & & & & & & & & \\
\hline MC3 & 0.0 & 75 & 0.22 & 0.214 & & & & & & & & \\
\hline
\end{tabular}

Source: Authors own calculation

The result shows the significance of the size effect in explaining variations in portfolio return and that its contribution tends to be greater for small portfolios (S/L, $\mathrm{S} / \mathrm{M}, \mathrm{S} / \mathrm{H})$ than for medium portfolios $(\mathrm{M} / \mathrm{L}, \mathrm{M} / \mathrm{M}, \mathrm{M} / \mathrm{H})$ and big size portfolios $(\mathrm{B} / \mathrm{L}, \mathrm{B} / \mathrm{M}, \mathrm{B} / \mathrm{H})$. The findings of this study are similar to the small firm effect theory which explains smaller firms perform better than larger firms do. Moreover, 
it is noticed that the $S M B_{t}$ is negative relative to the stock returns and this finding is consistent with the earlier findings of Wang and $\mathrm{Xu}$ (2004). One plausible explanation for the present finding is that smaller firms have a greater amount of growth opportunities and have a tendency to be more volatile compared to their peers of larger firms. Earlier, Ajlouni and Khasawneh (2017), Kilsgard and Wittorf (2010), Drew et al. (2003) and Fama and French (1993) conclude with similar notation.

Table 5: Summary of Adjusted R2 for the Year 2014 to 2018.

\begin{tabular}{|c|c|c|c|c|c|c|c|c|c|}
\hline Model & \multicolumn{10}{|c|}{ CAPM } \\
\hline Portfolio & $\mathrm{S} / \mathrm{L}$ & $\mathrm{S} / \mathrm{M}$ & $\mathrm{S} / \mathrm{H}$ & $\mathrm{M} / \mathrm{L}$ & $\mathrm{M} / \mathrm{M}$ & $\mathrm{M} / \mathrm{H}$ & $\mathrm{B} / \mathrm{L}$ & $\mathrm{B} / \mathrm{M}$ & $\mathrm{B} / \mathrm{H}$ \\
\hline Adjusted R & 0.0461 & 0.1306 & 0.0971 & 0.1037 & 0.1814 & 0.1589 & 0.0738 & 0.2165 & 0.1917 \\
\hline Model & \multicolumn{8}{|c|}{ The CAPM augmented with SMB } \\
\hline Adjusted $\mathrm{R}^{2}$ & 0.452 & 0.5563 & 0.613 & 0.149 & 0.2186 & 0.272 & 0.075 & 0.2203 & 0.2136 \\
\hline
\end{tabular}

Source: Authors own calculation

Table 5 shows the summary result of the adjusted $R^{2}$ value in time series regression. The average adjusted $\mathrm{R}^{2}$ of nine portfolios in the CAPM model is $13.33 \%$, besides this when the size premium factor is added in the CAPM model average adjusted $\mathrm{R}^{2}$ value of nine portfolios raises significantly from $13.33 \%$ to $30.78 \%$. For only small size (S/L, S/M, S/H) portfolio average adjusted $\mathrm{R}^{2}$ value reaches $54.04 \%$, for medium portfolios $(\mathrm{M} / \mathrm{L}, \mathrm{M} / \mathrm{M}, \mathrm{M} / \mathrm{H})$ it increases from $14.82 \%$ to $21.32 \%$. However, for big-size portfolios $(\mathrm{B} / \mathrm{L}, \mathrm{B} / \mathrm{M}, \mathrm{B} / \mathrm{H})$ adjusted $\mathrm{R}^{2}$ value before and after adding "size" premium is observed $16.06 \%$ and $16.96 \%$, are almost identical.

\section{Conclusion}

In this paper, we examined standard CAPM and "size" augmented CAPM in the Dhaka Stock Exchange. We used data from the DSE for the period starting from January 1, 2014, to December 31, 2018. Following Fama and French (1993) methodology, we have construct nine different portfolios and applied the OLS method in regression analysis. In order to estimate the factor models time series regression test is done. Our results show that "size" augmented CAPM performs better in explaining stock returns than the traditional CAPM in frontier market DSE. In addition, our results showed that overall market risk "beta" and firm size together have a significant impact on price formation in DSE. Here, the most important result is that the size and the sign of the individual factor loadings could differ across cross-sectional groups. For the sampling period as a whole, the size premium (i.e. the perceived tendency of small-cap stock to outperform their medium- and largecap counterparts) was found to be largest among stocks with below-average market capitalization. This finding reaffirms the existence of "size" anomaly which coincides with recent finding by C. Ang (2018), Atanasov and Nitschka (2017). To the end, from the empirical evidence, we might opine that the inclusion of size premium can craft traditional capital asset pricing model more effective and may improve the description of the frontier market DSE. Future research should examine 
the impact of size premium on time-varying parameters on expected asset returns in the Dhaka Stock Exchange.

\section{References}

[1] Acheampong, Prince, and Swanzy, Sydney, Kwesi. (2016). An Empirical Investigation into the Applicability of Fama-French Three Factor Model in Explaining Portfolio Returns: Evidence from Non-Financial Firms on the Ghana Stock Exchange. International Journal of Financial Research. 7(1), pp. 75-85.

[2] Ajlouni, Moh'd, Mahmoud., and Khasawneh, Maher, (2017). Empirical Test of Fama and French Three-Factor Model in Amman Stock Exchange. European Scientific Journal. Special Edition. pp.78-106.

[3] Ang, C. (2018). The absence of a size effect relevant to the cost of equity. Business Valuation Review, 37(3), pp. 87-92. https://doi.org/10.5791/BVRD-17-00013.1

[4] Ansari, Valeed, A. (2000). Capital Asset Pricing Model: Should We Stop Using It? Vikalpa. 25 (1), pp. 55-64.

[5] Atanasov,V. and Nitschka, T. (2017), Firm size, economic risks, and the crosssection of international stock returns, The North America Journal of Economics and Finance, 39, pp. 110-126.

[6] Bajpai, S., and Sharma, A., K. (2015). An Empirical Testing of Capital Asset Pricing Model in India. Procedia - Social and Behavioral Sciences, 189, pp. 259-265.

[7] Banz, R., W. (1981). The relationship between return and market value of common stocks. Journal of Financial Economics, 9(1), pp. 3-18.

[8] Bartholdy, J. and Peare, P. (2005). Estimation of expected return: CAPM vs. Fama and French, International Review of Financial Analysis, 14(4), pp. 407427.

[9] Basiewicz, P., G. and Auret, C., J. (2010). Feasibility of the Fama and French three factor model in explaining returns on the JSE. Investment Analysts Journal, 39(71), pp.13-25.

[10] Bhatnagar, Chandra, Shekhar, and Ramlogan, Riad, (2012). The capital asset pricing model versus the three factor model: A United Kingdom Perspective, International Journal of Business and Social Research, 2(1), pp. 51-65.

[11] Brailsford, T., Gaunt, C., and O'Brien, M.A. (2012). Size and book-to-market factors in Australia, Australian Journal of Management, 37(2), pp.261-281.

[12] Cakici, N. and Tan, S., (2014). Size, value, and momentum in developed country equity returns: Macroeconomic and liquidity exposures", Journal of International Money and Finance, 44, pp. 179-209.

[13] Chiah, M., Chai, D., Zhong, A., and Li, S. (2016). A Better Model? An Empirical Investigation of the Fama-French Five-factor Model in Australia, International Review of Finance, 16(4), pp. 594-638. 
[14] Cochrane, J., H. (2005), Asset Pricing: Revised Edition, United Kingdom: Princeton University Press,

[15] Connor, G. and Sehgal, S. (2003). Tests of the Fama and French Model in India, Decision, 30(2), pp.1-20.

[16] De Moor, L. and Sercu, P. (2013). The smallest firm effect: An international study, Journal of International Money and Finance, 32(C), pp.129-155.

[17] Dimson, E. and Marsh, P. (1999). Murphy's law and market anomalies, Journal of Portfolio Management, 25(2), pp. 53-69.

[18] Djajadikerta, Hadrian, G. and Nartea, Gilbert, V. (2005).The Size and Bookto-Market Effects and the Fama- French Three-Factor Model in Small Markets: Preliminary Findings from New Zealand. Working Paper No. 0510, School of Business, Edith Cowan University.

[19] Dou, P.Y., Gallagher, D.R. and Schneider, D.H. (2013). Dissecting anomalies in the Australian stock market, Australian Journal of Management, 38(2), pp. 353-373.

[20] Drew, M., E., Naughton, T. and Veeraraghavan, M. (2003). Firm size, bookto-market equity and security returns: evidence from the Shanghai Stock Exchange. Australian Journal of Management, 28(2), pp. 119-139.

[21] Eraslan, V. (2013). Fama and French Three-Factor Model: Evidence from Istanbul Stock Exchange. Business and Economics Research Journal, 4(2), pp. 11-22.

[22] Fama, E. F., and French, K. R. (1992). The Cross-Section of Expected Stock Returns. THE JOURNAL OF FINANCE, 47(2), pp. 427-465.

[23] Fama, E. F., and French, K. R. (1993). Common risk factors in the returns on stocks and bonds. Journal of Financial Economics, 33(1), pp. 3-56.

[24] Fama, E.F., \& French, K.R. (2012). Size, Value, and Momentum in International Stock Returns. Fama-Miller Working Paper, Tuck School of Business Working Paper No. 2011-85.

[25] Gabriel, Fernanda, Sousa. (2014). And the Winner is ... "CAPM, FAMA and French Three-Factor or Reward Beta"? International Journal of Advances in Management and Economics, 3(4), pp.70-60.

[26] Gaunt, C. (2015). The illusory Australian small firm premium, JASSA: The Journal of the Securities Institute of Australia, 2, pp.19-25.

[27] Gupta, O. P., and Sehgal, S. (1993). An empirical testing of capital asset pricing model in India. Finance India, 7(4), pp.863-874.

[28] Hanif, M. and Bhatti, U. (2010). Validity of Capital Assets Pricing Model: Evidence from KSE-Pakistan. European Journal of Economics, 20. pp. 148161.

[29] Hasan, M.Z., Kamil A.A., Mustafa A. and Baten, M., A. (2011). A Validity Test of Capital Asset Pricing Model for Dhaka Stock Exchange. Journal of Applied Sciences. 11(20), pp. 3490-3496.

[30] Hirshleifer, D. (2001). Investor Psychology and Asset Pricing, Journal of Finance, 56, pp.1533-1597. 
[31] Horowitz, J. L., Loughran, T. and Savin, N., E. (1999). The disappearing size effect, Research in Economics, Elsevier, 54(1), pp. 83-100.

[32] Minovic, J. and Zivkovic, B. (2012). Impact of Liquidity And Size Premium On Equity Price Formation In Serbia, Economic Annals, 57(195), pp. 43-78.

[33] Karp, A., and Vuuren, G., U. (2017). The Capital Asset Pricing Model And Fama-French Three Factor Model In An Emerging Market Environment. International Business \& Economics Research Journal. 16(3), pp.231-256.

[34] Keim, D., B. (1983). Size related anomalies and stock return seasonality: Further Empirical Evidence. Journal of Financial Economics (12), pp. 13-32.

[35] Kilsgard, David, and Wittorf, Filip. (2010). The Fama and French ThreeFactor Model-Evidence from the Swedish Stock Market. Master Thesis. Lund University, Department of Business Administration,

[36] Lintner, John. (1965). The Valuation of Risk Assets and the Selection of Risky Investments in Stock Portfolios and Capital Budgets. The Review of Economics and Statistics, 47(1), PP. 13-37.

[37] Neumann, John, Von. and Morgenstern, Oskar. (1944). Theory of Games and Economic Behavior. Princeton, NJ: Princeton University Press.

[38] Pena, F., J., D., Forner, C., and Espinosa, G., L. (2010). Fundamentals and the Origin of Fama-French Factors: The Case of Spanish Market. Czech Journal of Economics and Finance, 60(5), pp. 426-446.

[39] Reinganum, M., R. (1981). Misspecification of Capital Asset Pricing: Empirical Anomalies Based on Earnings' Yields and Market Values. Journal of Financial Economics, 9(1), pp.19-46.

[40] Schultz, P. (1983). Transaction costs and the small firm effect: A comment, The Journal of Financial Economics, 12(1), pp. 81-88.

[41] Schwert, G., W. (2003). Anomalies and Market Efficiency In: Constantinides, G.M., Harris, M., Stulz, R.M. (Eds.), Handbook of the Economics of Finance. Amsterdam, North Holland.

[42] Sharpe, William, F. (1964). Capital Asset Prices: A Theory of Market Equilibrium under Conditions of Risk, The Journal of Finance, XIX (3), PP. 425-442.

[43] Stoll, H., and Whaley, R., E. (1983). Transaction costs and the small firm effects, Journal of Financial Economics, 12(1), pp. 57-79.

[44] Wang, Fenghua, and Xu, Yexiao. (2004). What Determines Chinese Stock Returns? Financial Analysts Journal, 60(6), PP. 65-77.

[45] Williams, J.B. (1938). The Theory of Investment Value. Cambridge, MA: Harvard University Press. 